\title{
Thoracic Saccular Aortic Aneurysm Presenting with Recurrent Laryngeal Nerve Palsy prior to Aneurysm Rupture: A Prodrome of Thoracic Aneurysm Rupture?
}

\author{
Masafumi Ohki \\ Department of Otolaryngology, Saitama Medical Center, 1981 Kamoda, Kawagoe-shi, \\ Saitama 350-8550, Japan \\ Correspondence should be addressed to Masafumi Ohki, m-ohki@umin.ac.jp
}

Received 3 January 2012; Accepted 12 February 2012

Academic Editors: G. Paludetti and H. Sudhoff

Copyright ( $) 2012$ Masafumi Ohki. This is an open access article distributed under the Creative Commons Attribution License, which permits unrestricted use, distribution, and reproduction in any medium, provided the original work is properly cited.

Left recurrent laryngeal nerve palsy rarely results from cardiac disease. We present 2 cases of left recurrent laryngeal nerve palsy caused by thoracic saccular aortic aneurysms. One patient suffered an aortic aneurysm rupture one month after the advent of hoarseness, necessitating emergency surgery with aortic arch replacement. The other patient underwent elective aortic arch replacement surgery. Both saccular aortic aneurysms protruded downward in the aortopulmonary window to compress the recurrent laryngeal nerves. This is only the 5th case report of the rare occurrence of acute recurrent laryngeal nerve palsy subsequent to saccular aneurysm rupture in the English literature. Recurrent laryngeal nerve palsy does not always indicate imminent aneurysm rupture, but should trigger awareness of a potential rupture in the near future. Left recurrent laryngeal nerve palsy might be a prodrome of aneurysm rupture.

\section{Introduction}

Hoarseness is rarely caused by cardiovascular diseases. Ortner first reported hoarseness due to paralysis of the left recurrent laryngeal nerve caused by a dilated left atrium in mitral stenosis [1]. Recurrent nerve palsy secondary to cardiovascular diseases is called Ortner's syndrome. The primary cardiovascular diseases related to recurrent laryngeal nerve palsy are mitral valve disorders, for example, mitral stenosis, cor pulmonale, pulmonary hypertension, aortopulmonary window, Ebstein's anomaly, aortic aneurysm, aortic dissection, and so on $[2,3]$. We experienced 2 rare cases of hoarseness due to left recurrent laryngeal nerve paralysis caused by thoracic saccular aortic aneurysms. One patient manifested acute occurrence of hoarseness and subsequent aneurysm rupture. There are only 4 such case reports of acute recurrent laryngeal nerve palsy with subsequent saccular aneurysm rupture in the English literature [47]. We discuss the features of these cases and our experience.

\section{Case Presentation}

2.1. Case 1. A 77-year-old man presented with a 1-month history of hoarseness, sputa, and aspiration. He had no history of severe chest or back pain. His medical history included chronic renal failure, requiring maintenance hemodialysis. Fiberoptic laryngoscopy revealed left vocal cord palsy in the intermediate position. Magnetic resonance imaging (MRI) of the brain and cervix showed normal findings. Chest X-ray showed a widened mediastinum. MRI of the chest revealed a thoracic aortic saccular aneurysm protruding downward in the aortopulmonary window (Figure 1). Ten days later, he presented chest pain and computed tomography (CT) of the chest showed an enlarged aortic saccular aneurysm, protruding downward, surrounded by a hematoma in the aortopulmonary window (Figure 2). He was diagnosed as having a ruptured thoracic aortic arch aneurysm. He underwent urgent surgery for replacement of the ascending aorta and the aortic arch by blood vessel prosthesis. The aorta consisted of a thrombotic 


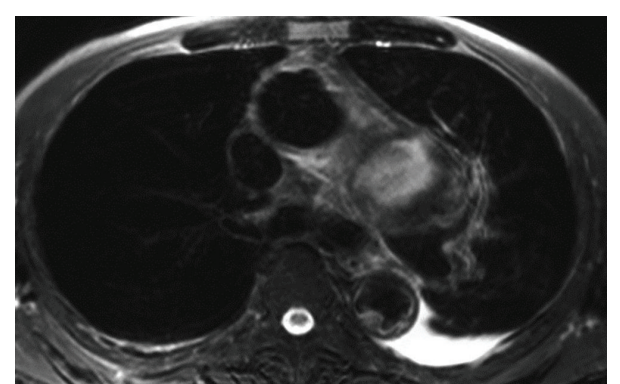

FIgure 1: Transverse MRI (T2-weighted image) of the chest revealing a thoracic aortic saccular aneurysm protruding downward in the aortopulmonary window.

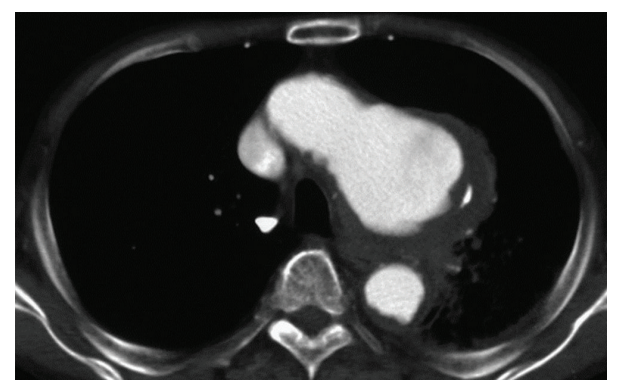

Figure 2: Transverse contrast-enhanced CT of the chest showing an enlarged aortic saccular aneurysm, protruding downward, surrounded by a hematoma in the aortopulmonary window.

saccular aneurysm compressing the main pulmonary arteries in the arch of the aorta and severe atherosclerosis extended from the ascending aorta to the distal aortic arch. Recurrent laryngeal nerve palsy persists, to date, 1 month after surgery.

2.2. Case 2. An 85-year-old female manifested hoarseness for 1 month. She had no history of severe chest or back pain. Fiberoptic laryngoscopy revealed left recurrent laryngeal nerve palsy in the abducted position. Chest X-ray showed a widened mediastinum. CT of the chest revealed a thoracic aortic saccular aneurysm, protruding downward, in the aortopulmonary window (Figure 3). She underwent surgery for replacement of the distal aortic arch by blood vessel prosthesis. The distal arch of the aorta consisted of an atherosclerotic saccular aneurysm, which was $40 \mathrm{~mm}$ in diameter, protruding downward and compressing the recurrent laryngeal nerve. The recurrent laryngeal nerve palsy persists, to date, 10 days after surgery.

\section{Discussion}

A true aneurysm involves all 3 layers of the arterial blood vessel wall. Shapes are described as fusiform or saccular type. A fusiform aneurysm balloons out on all sides of the aorta, while a saccular aneurysm bulges or balloons out on one side. Constant pressure from blood, ejected from the heart, continuously presses the already weakened aneurysm wall. An aneurysm gradually increases in size, progressively weakening the aneurysm wall. Aneurysms have a potential

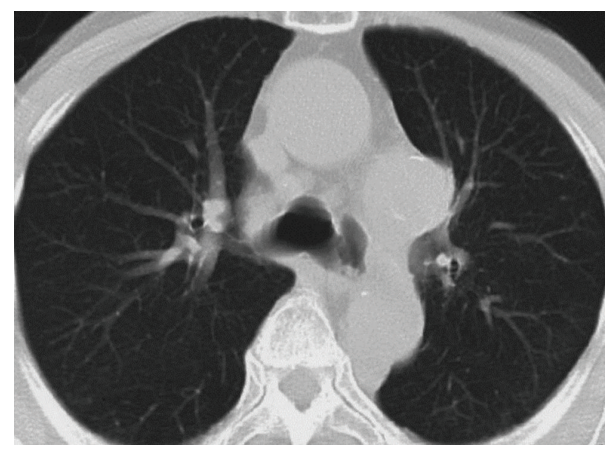

FIgURE 3: Transverse CT of the chest showing an aortic saccular aneurysm, protruding downward, in the aortopulmonary window.

risk for rupture or dissection, which can lead directly to death unless urgent surgery is carried out. Even when surgery for aneurysm rupture is performed, the fatality rate is high. Recurrent nerve palsy due to thoracic aortic aneurysm is an unusual complication. Thoracic aortic aneurysm is the cause of recurrent nerve palsy in $5 \%$ of cases [4]. The mechanism of left recurrent laryngeal nerve palsy has not as yet been clarified. However, it is attributed to compression of the left recurrent laryngeal nerve hooking around the ligamentum arteriosum between the pulmonary artery and aorta via aneurysm enlargement [3]. In our cases, saccular aneurysms protruded into the space between the pulmonary artery and aortic arch, apparently compressing the recurrent nerve. The advent of recurrent laryngeal nerve palsy in patients with cardiovascular diseases requires prompt detailed examination because it suggests possible aneurysm dilation. Aortic aneurysms are life threatening in cases with rupture. When recurrent nerve palsy occurs, is it a warning sign of aneurysm rupture? In case 1 , a thoracic aneurysm ruptured 1 month after the advent of hoarseness. Some reports described aneurysms as rupturing 0 to 3 days after the onset of recurrent laryngeal nerve palsy [4-6], whereas aneurysm rupture could be avoided if recurrent laryngeal nerve palsy prompted elective surgery 1 month to 1 year after its onset $[4,7-11]$. Chan reported that death occurred after severe chest pain and subsequent hypotension 1 year after manifestation of recurrent laryngeal nerve palsy in a patient with an aneurysm [12]. Texido described 8 patients with hoarseness due to an aneurysm and one suffered a rupture 1 day after the onset of hoarseness [4]. Recurrent laryngeal nerve palsy does not always mean imminent aneurysm rupture. However, rupture can be imminent. We may regard recurrent nerve palsy as a prodrome of aneurysm rupture. Surgical treatments are mainly of 2 types, that is, conventional open chest surgery and endovascular surgery. Patients may recover from recurrent laryngeal nerve palsy 6 to 12 months after both types of surgery, but this is not always the case $[8,9,13-15]$.

\section{Conclusion}

Left recurrent nerve palsy can arise from a thoracic saccular aortic aneurysm. Thoracic saccular aortic aneurysm is 
an important factor in making the differential diagnosis of recurrent nerve palsy. It might be a prodrome of aneurysm rupture necessitating emergent management.

\section{Conflict of Interests}

The author declares that there is no conflict of interests.

\section{References}

[1] N. Ortner, "Recurrent laryngeal nerve paralysis due to mitral value stenosis," Wien Klin Wochenschr, vol. 10, pp. 753-755, 1897.

[2] H. Hirose, "Clinical observations on 600 cases of recurrent laryngeal nerve paralysis," Auris Nasus Larynx, vol. 5, no. 1, pp. 39-48, 1978.

[3] S. K. Mulpuru, B. C. Vasavada, G. K. Punukollu, and A. G. Patel, "Cardiovocal syndrome: a systematic review," Heart Lung and Circulation, vol. 17, no. 1, pp. 1-4, 2008.

[4] M. T. Teixido and J. P. Leonetti, "Recurrent laryngeal nerve paralysis associated with thoracic aortic aneurysm," Otolaryngology-Head and Neck Surgery, vol. 102, no. 2, pp. 140-144, 1990.

[5] C. Lydakis, E. Thalassinos, S. Apostolakis, E. Athousakis, E. Michou, and E. Kontopoulou, "Hoarseness as imminent symptom of aortic aneurysm rupture (Ortner's syndrome)," International Angiology, vol. 25, no. 2, pp. 231-233, 2006.

[6] Y. Nishimura, Y. Okamura, S. Uchita, and K. Honda, "Abrupt rupture of an aortic arch aneurysm into the pulmonary artery," European Journal of Cardio-thoracic Surgery, vol. 36, no. 1, pp. 212-213, 2009.

[7] O. Kamp, A. C. Van Rossum, and R. Torenbeek, "Transesophageal echocardiography and magnetic resonance imaging for the assessment of saccular aneurysm of the transverse thoracic aorta," International Journal of Cardiology, vol. 33, no. 2, pp. 330-333, 1991.

[8] W. K. Lew, K. Patel, O. P. Haqqani, and F. A. Weaver, "Endovascular management of hoarseness due to a thoracic aneurysm: case report and review of the literature," Vascular and Endovascular Surgery, vol. 43, no. 2, pp. 195-198, 2009.

[9] K. Stoob, H. Alkadhi, M. Lachat, S. Wildermuth, and T. Pfammatter, "Resolution of hoarseness after endovascular repair of thoracic aortic aneurysm: a case of Ortner's syndrome," Annals of Otology, Rhinology and Laryngology, vol. 113, no. 1, pp. 4345, 2004.

[10] W. S. Kuan, S. K. Lee, and S. B. Suat Ooi, "Chronic voice hoarseness: when is it an emergency?" European Journal of Emergency Medicine, vol. 14, no. 6, pp. 360-362, 2007.

[11] O. Gulel, M. Elmali, S. Demir, and B. Tascanov, "Ortner's syndrome associated with aortic arch aneurysm [4]," Clinical Research in Cardiology, vol. 96, no. 1, pp. 49-50, 2007.

[12] P. Chan, C. P. Lee, J. T. Ko, and J. S. Hung, "Cardiovocal (Ortner's) syndrome left recurrent laryngeal nerve palsy associated with cardiovascular disease," The European Journal of Medicine, vol. 1, no. 8, pp. 492-495, 1992.

[13] J. P. Morales, Y. C. Chan, R. E. Bell, J. F. Reidy, and P. R. Taylor, "Endoluminal repair of distal aortic arch aneurysms causing aorto-vocal syndrome," International Journal of Clinical Practice, vol. 62, no. 10, pp. 1511-1514, 2008.

[14] A. S. Thirlwall, “Ortner's syndrome: a centenary review of unilateral recurrent laryngeal nerve palsy secondary to cardiothoracic disease," Journal of Laryngology and Otology, vol. 111, no. 9, pp. 869-871, 1997.
[15] R. F. Chen, C. T. Lin, and C. H. Lu, "Ortner's syndromea rare cause of unilateral vocal cord paralysis: a case report," Kaohsiung Journal of Medical Sciences, vol. 25, no. 4, pp. 203206, 2009. 


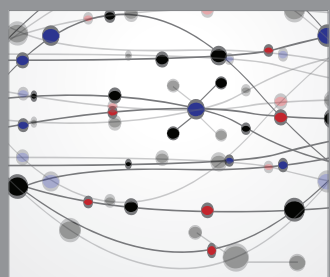

The Scientific World Journal
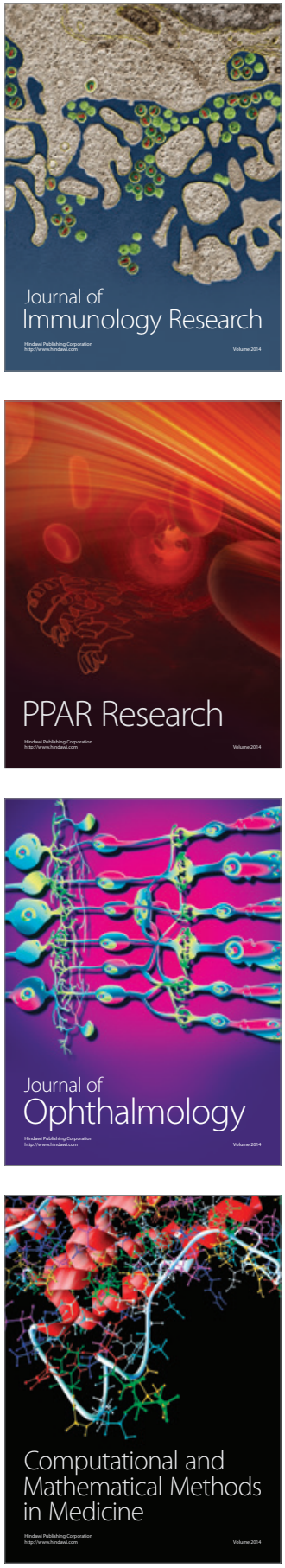

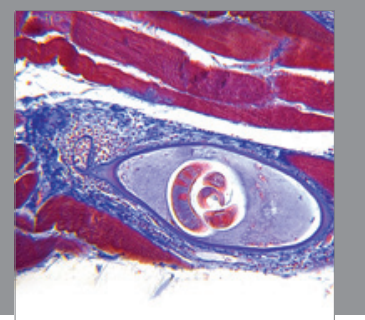

Gastroenterology

Research and Practice
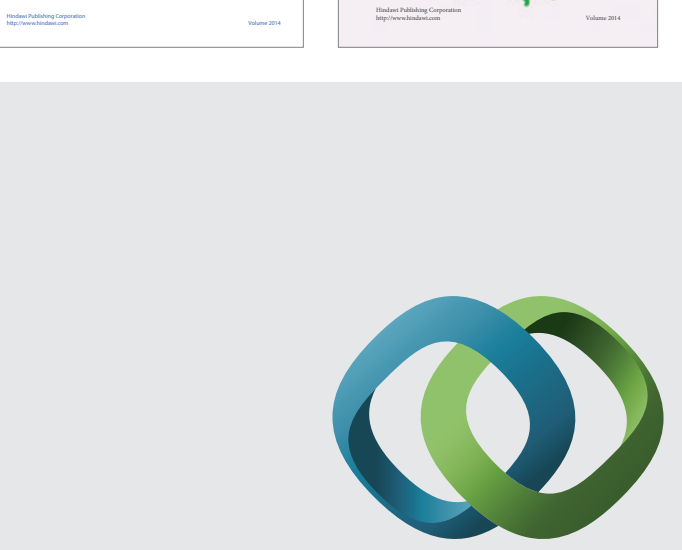

\section{Hindawi}

Submit your manuscripts at

http://www.hindawi.com
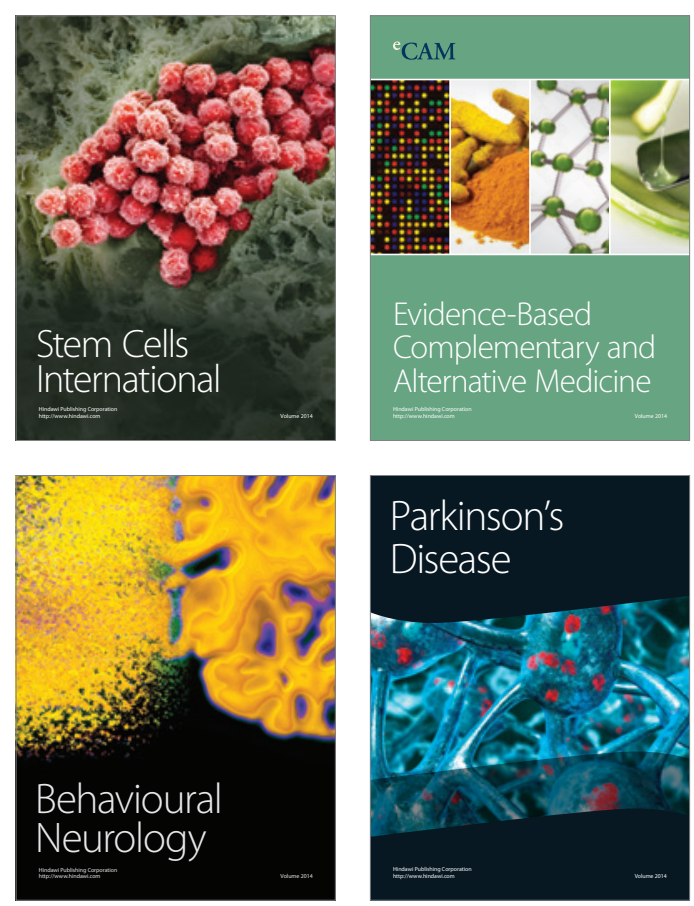

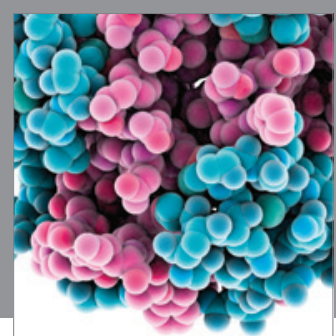

Journal of
Diabetes Research

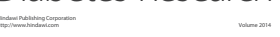

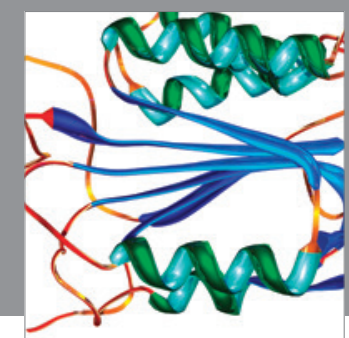

Disease Markers
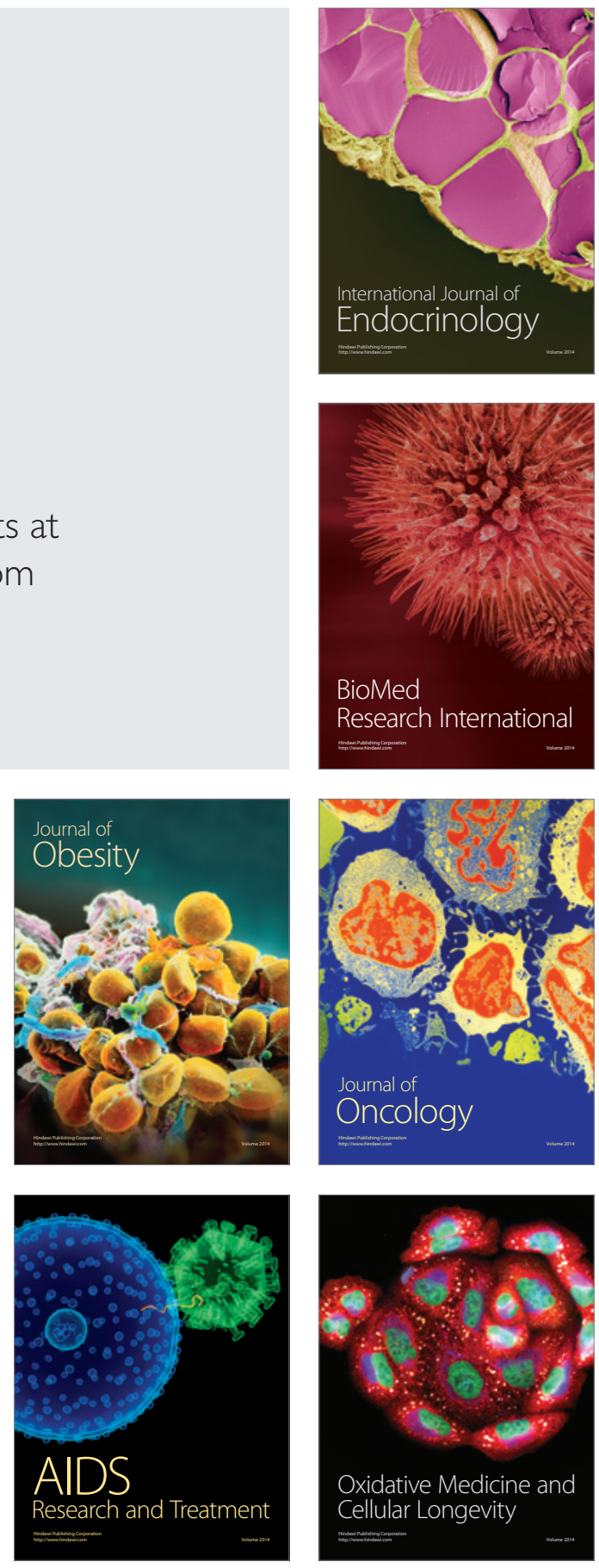